\title{
A sociologia dos agenciamentos mercantis e a contribuição de Michel Callon para o estudo dos mercados*
}

\author{
Marcelo Sampaio Carneiro**
}

Resumo: Este artigo discute os principais elementos de uma nova perspectiva teórica para o estudo dos mercados, a sociologia dos agenciamentos mercantis de Michel Callon. Nele, destaco alguns pontos dessa abordagem, que, partindo da crítica aos estudos dos mercados como interfaces, propõe pensá-los como agenciamentos mercantis, entendidos como um conjunto de cadrages, que envolvem operações que precedem e ultrapassam o momento das operações de compra e venda. Outrossim, procuro mostrar que alguns elementos de originalidade dessa abordagem encontram-se presentes em outras perspectivas da nova sociologia econômica e questiono algumas de suas teses sobre as possibilidades de intervenção no funcionamento dos mercados.

Palavras-Chave: Mercados. Sociologia econômica. Performatividade. Cadrages. Dispositivos de cálculo.

\section{The sociology of markets agencements and the contribution of Michel Callon to the study of markets}

Abstract: This article discusses a new theoretical perspective for the study of markets, Michel Callon's sociology of market agencements. It highlights the main elements of this approach which, by criticizing the studies of markets as interactions, proposes to think about them as market agencements, understood as a set of cadrages, which comprise operations that precede and go beyond the encounter between sellers and buyers. Additionally, I show that some original aspects of this approach can be found in other perspectives of the economic sociology and question some of Callon's thesis about the possibilities of intervention in the functioning of markets.

Key words: Markets. Economic sociology. Performativity. Cadrages. Calculation devices.

\section{Introdução}

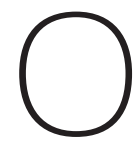

lançamento do livro L'emprise des marchés. Comprendre leur fonctionnement pour pouvoir les changer, de Michel Callon (2017), marca o coroamento de um trabalho de investigação sobre o funcionamento dos mercados, que se iniciou nos anos 1980 no âmbito do Centro de Sociologia da Inovação (CSI) da Escola de Minas de Paris, ao mesmo tempo em que pretende consolidar
Recebido: 10.04.18 Aprovado: 08.04.19

\author{
* Agradeço \\ as sugestões \\ apresentadas por \\ Rodrigo Santos, \\ Cristiano Monteiro, \\ Juarez Carvalho Filho \\ para a elaboração \\ do artigo. Espero \\ ter conseguido \\ incorporar, ao \\ menos parcialmente, \\ suas estimulantes \\ observações. Sou \\ grato também \\ aos pareceristas \\ anônimos de \\ Sociedade e \\ Estado, cujas \\ recomendações \\ permitiram que 0 \\ artigo tomasse o seu \\ formato atual. \\ ** Marcelo Sampaio \\ Carneiro é professor \\ do Departamento \\ de Sociologia e \\ Antropologia da \\ Universidade Federal \\ do Maranhão \\ (UFMA), São Luís, \\ Maranhão, Brasil. \\ Orcid: 0000- \\ 0002-7474-2694. \\ <mdscarneiro@uol. \\ com.br>.
}


1. Realizei todas as traduções dos originais escritos em francês.

2. Optei por manter a designação do conceito em francês, por acreditar que seu equivalente na língua portuguesa (enquadramento) não transmitiria o significado pretendido pelo autor. De acordo com Callon, o conceito de cadrage - tal como utilizado pela teoria do ator-rede - foi elaborado a partir da noção desenvolvida por Goffman e pretende dar conta dos diferentes actantes (humanos e não humanos) que constrangem as interações, "evitando transbordamentos, agindo, ao mesmo tempo, como um dispositivo de conexão" (Callon, 2006: 273).

3. Neologismo utilizado para dar conta das dimensões qualitativas e quantitativas que estão presentes no processo de avaliação e qualificação dos bens. Essa expressão foi desenvolvida originalmente no artigo sobre o papel dos dispositivos de cálculo escrito por Callon \& Muniesa (2003). um paradigma de análise denominado sociologia dos agenciamentos mercantis e estimular uma agenda de novos temas de estudos.

Mais conhecido pelas pesquisas no campo dos estudos sobre a inovação (Callon, 1986), o investimento de Callon em questões relacionadas à sociologia econômica remonta aos anos 1990, com os artigos que, individualmente ou em colaboração, consagrou à discussão acerca do papel da ciência econômica na performatização dos fatos econômicos (Callon, 1998a; 1998b; Muniesa \& Callon, 2009) ou ao debate francês sobre a chamada economia da qualidade (Callon et alii, 2013).

Contudo, como o próprio título sugere - "O domínio dos mercados" -, o propósito de Callon nessa obra vai além da exposição da teoria dos agenciamentos mercantis, proposta que ele já havia apresentado em artigo anterior (Callon, 2013) e que foi publicada em obra coletiva reunindo os principais trabalhos desenvolvidos por pesquisadores do CSI sobre o funcionamento de dispositivos mercantis, submetendo também à apreciação sua visão sobre como seria possível lidar com a presença crescente dos mercados na vida moderna.

Ao discutir a questão do domínio dos mercados na vida contemporânea, Callon apresenta duas possibilidades de crítica e intervenção, já presentes na obra de Karl Polanyi (2000). Uma pretende impedir a expansão dos mercados através de seu isolamento das demais esferas da vida social; outra - que ele acha mais efetiva - aposta na possibilidade de modificação dos mercados, mediante a intervenção na maneira como funcionam e nos efeitos que produzem, através do que denomina de uma "engenharia política dos agenciamentos mercantis". Ou seja, para Callon, a questão central é a da possibilidade de modificação na concepção dos mercados,

que deve responder a um caderno de encargos contendo um conjunto de exigências potencialmente contraditórias e cuja formulação é regularmente submetida ao debate público (Callon, 2013: 327) ${ }^{1}$.

No caso dessa engenharia política dos agenciamentos mercantis, o foco se direciona para o disciplinamento dos mercados através de intervenções nos diferentes mecanismos de cadrage $e^{2}$ apresentados por Callon - passivação mercantil, ativação de agências de qualcul ${ }^{3}$, organização dos encontros, singularização dos bens e formulação dos preços - e que apresentarei com mais detalhes na primeira seção desse artigo. No último capítulo de O domínio dos mercados são apresentados três casos a partir dos quais é realizada a discussão do controle dos mercados a partir da perspectiva dos agenciamentos mercantis: o mercado financeiro, os 
dispositivos de contenção do aquecimento climático global e os mercados para produtos agrícolas transgênicos.

Neste artigo, exponho os elementos centrais da argumentação desenvolvida por Callon para a construção da sociologia dos agenciamentos mercantis (Callon, 2013; 2017). De início, destaco o debate que o autor estabelece com as abordagens que estudam os mercados como relações de interface (Seção 1); a definição dos principais tipos de cadrages do agenciamento mercantil - passiva-ação, agências de cálculo, organização de encontros, envolvimento e desinteresse, formulação dos preços (Seção 2) -; a dinâmica dos agenciamentos mercantis (Seção 3); a dimensão política dos agenciamentos mercantis, a partir dos casos acima indicados (Seção 4). Ao final, apresento uma reflexão sobre a proposta teórica, procurando situá-la nos debates mais gerais acerca da sociologia dos mercados (Fourcade, 2007; Beckert, 2009; Fligstein \& Dauter, 2012; Steiner, 2005; 2018), e discuto algumas de suas teses sobre as possibilidades de intervenção no funcionamento dos mercados.

A análise da contribuição de Callon para o desenvolvimento da sociologia dos mercados foi realizada a partir do levantamento de trabalhos do autor sobre essa temática (Callon, 2017; 2013; 2012; 2009; 1998a; 1998b; 1991), de escritos elaborados com colaboradores (Callon, Méadel \& Rabeharisoa, 2013; Callon \& Muniesa, 2003; Muniesa \& Callon, 2009) e em obra coletiva que discute a contribuição de Callon para os estudos sociais da ciência e a sociologia econômica (Akrich, 2010).

\section{Do mercado-interface}

\section{aos agenciamentos mercantis}

No primeiro capítulo de L'emprise des marchés, Callon faz uma breve revisão do que considera as principais contribuições de estudos de economia, sociologia e antropologia para a compreensão do funcionamento dos mercados. Diz que essas abordagens apresentam em comum a análise da transação mercantil como relação de interface, que ele designa como mercado-interface e cujas principais características seriam:

i. pensar os agentes como vendedores e compradores;

ii. considerar que esses agentes estão em concorrência para a efetivação de transações; 
iii. que consistem na transferência (de direitos de propriedade) de bens e serviços;

iv. transações essas que são finalizadas por pagamentos monetários e sustentadas por arranjos institucionais (Callon, 2017: 38-39).

Argumenta ainda que a abordagem do mercado-interface apresenta duas outras características-chave, considerando oferta e demanda como esferas autônomas e aborda as duas como articuladas por bens que funcionam como plataformas.

Apesar de reconhecer a validade relativa dessa explicação, Callon aponta duas falhas principais, pois, nesse tipo de caracterização do mercado não se discute a questão do processo de qualificação e singularização dos bens, ao mesmo tempo em que pouca importância é conferida ao papel dos dispositivos materiais no intercâmbio mercantil. Por conseguinte, o autor considera o conceito de mercado-interface inconsistente, elaborado a partir da perspectiva de uma "organização estruturada em torno de blocos e de bens de plataforma, com a competição assegurando a reprodução dessa estrutura" (Callon, 2017: 42).

Segundo Callon, a teoria dos agenciamentos mercantis não desconsidera a visão do mercado-interface, reconhecendo o valor de suas aquisições teóricas, contudo, procura ir além, através da observação de um conjunto de mecanismos e atividades que são objetivadas na discussão do processo de qualificação dos bens e no destaque conferido aos objetos na troca mercantil.

O conceito de agenciamento mercantil que proponho, para substituir o de mercado, tem por ambição sublinhar a diversidade de configurações (que a palavra agenciamento sugere) ao mesmo tempo em que sua unidade (que é o que indica o qualificativo de mercantil [...]). Aproximar-se dos mercados concretos, analisar a variedade de suas configurações e dos efeitos produzidos, tendo por objetivo a identificação das tomadas de posição que permitiriam agir sobre essa variedade [de agenciamentos], tal é o trabalho teórico que eu desejaria mostrar as linhas de desenvolvimento possíveis (Callon, 2013: 328).

Esses mercados concretos são pensados como dispositivos agonísticos nos quais são disputadas as definições acerca das qualificações dos bens. Nesse sentido, Callon analisa o mercado como um conjunto de operações a montante e a jusante do momento do encontro entre compradores, vendedores e o bem a ser vendido/ adquirido, envolvendo, portanto, muito mais participantes do que a visão habitual do mercado-interface. Para explicar como funciona o processo de agenciamento 
mercantil, o autor destaca um conjunto de atividades que ele designa como cadrages. Por conseguinte, cadrage designa dispositivos que orientam e estruturam a ação mercantil para sua finalidade estratégica, estabilizando temporariamente suas características. Nesse sentido, um cadrage tem o objetivo de conter transbordamentos e possíveis mudanças, de forma a estabilizar relações bilaterais e tornar o intercâmbio mercantil possível (Herlem, 2014).

\section{Os cinco cadrages do agenciamento mercantil}

Callon apresenta e discute cinco tipos de cadrages necessários ao agenciamento mercantil. São eles:
i. a passiva-ação ${ }^{4}$ mercantil;
ii. a avaliação por agências de cálculo (qualcul ou calqul);
iii. a organização dos encontros mercantis;
iv. o envolvimento (attachement) mercantil; e
v. a formulação de preços.

O primeiro cadrage descrito é o processo de passiva-ação. Ao trabalhar a partir de estudos antropológicos sobre a circulação dos bens - Jane Guyer, Arjun Appadurai, Igor Kopytoff -, Callon define a passiva-ação como as diversas operações de "mise en forme" que tornam a aquisição de um bem possível.

Esse processo de passiva-ação mercantil ${ }^{5}$ implica em alguns movimentos que visam separar os bens dos agentes - as chamadas operações de desvinculação (désintrication) - que lhe conceberam, produziram e colocaram em circulação e que preparam o bem para sua transferência ao consumidor, com a atribuição dos direitos de propriedade do bem ao comprador. Nesse ponto da argumentação, Callon aproxima a discussão da passiva-ação do conceito de mercadoria fictícia proposto por Polanyi, argumentando que todos os bens - e não apenas a terra, o trabalho e o dinheiro - oferecem algum tipo de resistência ao processo de passivação, ou seja, que todos necessitam algum tipo de investimento simbólico e material para se transformarem em mercadorias.

Para concluir a discussão sobre o movimento de passiva-ação, Callon chama atenção para as possíveis resistências a esse processo, como no caso dos efeitos inesperados ou desgastes associados à produção de sementes transgênicas ou aos

\author{
4. Callon utiliza \\ o neologismo \\ passiva $(c)$ tion ao \\ invés do termo \\ francês passivation \\ pelo fato de o \\ primeiro conferir \\ uma dimensão mais \\ ativa e dinâmica \\ ao processo que \\ ele pretende \\ descrever (Callon, \\ 2013: 348). Optei \\ por traduzir esse \\ neologismo pela \\ expressão passiva- \\ ação, pois creio \\ que se aproxima \\ dos objetivos \\ pretendidos pelo \\ autor. \\ 5. O que diferencia o \\ processo de passiva- \\ ação mercantil do \\ não mercantil é que \\ neste último o bem \\ circula e mantém \\ relação com os \\ agentes responsáveis \\ por sua concepção. \\ Nesse tipo de caso, \\ o bem pode ser \\ usufruído sem ser \\ alienado, como \\ ocorrem com os \\ bens de uso comum \\ (Callon, 2017: 83).
}


tratamentos médicos experimentais. Em ambas as situações, o aspecto central é a dificuldade em estabilizar tecnicamente as características dos seres (sementes e genes) a serem transformados em bens passíveis de comercialização. A dificuldade de passiva-ação dos seres vivos não humanos - como no caso da produção de sementes vegetais - está relacionada também às dificuldades na atribuição dos direitos de propriedade, uma vez que esta dependerá da discussão (metafísica) acerca da responsabilidade devida ao gênio humano ou aos processos naturais na produção dessa semente (Callon, 2013: 353).

O segundo cadrage é o das agências de cálculo, que, de acordo com a teoria dos agenciamentos mercantis, é um tema desconsiderado pela abordagem do mercado como interface, que ignora o papel desempenhado pelas ferramentas que os agentes utilizam "quando calculam suas escolhas" (Callon \& Muniesa, 2003: 191). Essa ideia de que os agentes "calculam escolhas" está baseada no argumento de que não existe diferença ente julgamento (qualitativo) e cálculo (quantitativo) e que as operações de escolha realizadas pelos agentes seriam mais bem descritas como operações de qualcul ou de calqul (Cochoy, 2002; 2011).

Por conseguinte, para Callon é necessário compreender como os agentes elaboram julgamentos e efetuam os cálculos que Ihes possibilitam introduzir ordem no universo dos bens e, dessa forma, participar do processo de passiva-ação. Nesse sentido, a agência de cálculo é entendida como entidade coletiva com equipamentos e instrumentos que permitem a identificação de semelhanças e diferenças entre os bens:

Esses equipamentos, que combinam apreciações qualitativas e cálculo numérico (deriva daí o neologismo qualcul), não são assimiláveis a simples instrumentos cuja única utilidade seria a de amplificar sem modificar as capacidades das pessoas humanas (Callon, 2017: 156).

Dois outros aspectos são centrais na compreensão das agências de cálculo, a saber, sua dimensão compósita (humanos + objetos) e a natureza das relações de poder que as perpassam. No primeiro caso, a teoria dos agenciamentos mercantis destaca que essas agências são cada vez mais um produto da interação entre humanos e próteses sociotécnicas (cognitivas ou materiais), como no exemplo do cliente no supermercado que utiliza um celular com software de reconhecimento do código de barras para identificar a origem de um determinado produto ou do cliente que, antes de ir ao supermercado, consulta um guia produzido por uma associação de consumidores. 
O segundo aspecto diz respeito à observação de que as agências de cálculo se encontram desigualmente distribuídas, o que leva ao estabelecimento de relações de dominação. Ao trabalhar no caso do cliente num supermercado, Callon observa, por exemplo, a existência de uma panóplia de agências de cálculo - embalagens com informações metrológicas, selos de qualidade social e/ou ambiental, organização das gôndolas etc. - que colocam os ofertantes em uma posição de superioridade frente ao consumidor. Diz, portanto, que como espaço agonístico, os agenciamentos mercantis são povoados de agentes dotados de armas desiguais e que existe um conjunto desses agentes que são desprovidos dos instrumentos de cálculo, encontrando-se,

dessa forma, em posição de fraqueza, dominadas por agências que calculam em seu lugar suas decisões e marcam com suas perspectivas a concepção dos bens submetidos à troca (Callon, 2017: 197).

Após analisar o papel das agências de cálculo, Callon passa a descrever o cadrage estabelecido pelos encontros mercantis. Partindo da crítica à abordagem do mercado-interface - que considera como variáveis importantes para entender a relação entre oferta e procura somente a frequência dos encontros e a circulação das informações -, a teoria dos agenciamentos mercantis sublinha a necessidade da observação mais amiúde das práticas comerciais e dos diversos momentos de encontro que preparam a acoplagem exitosa entre agentes da oferta e da procura (Callon, 2013: 366).

Nesse sentido, o elemento importante a ser considerado é o da existência de numerosas plataformas de encontro, que facilitam a coprodução do perfil (em termos de competências e qualidades) da oferta e da procura. Essas plataformas operam em diversos momentos, a jusante e a montante do ato da troca,

interagindo umas com as outras e elaborando por adições e transformações contínuas os ajustamentos que permitirão in fine a transação mercantil bilateral (Callon, 2017: 228).

Uma parcela importante de trabalhos de sociologia e antropologia econômica se interessou pela descrição desses dispositivos através dos quais os encontros mercantis se realizam - como no caso da descrição da economia do bazar (Geertz, 2003) e dos salões internacionais de vinhos (Garcia-Parpet, 2009), só para nos atermos a alguns exemplos. Contudo, para Callon são as plataformas de e-commerce, que, ao mesmo tempo em que esclarecem as características dos dispositivos mais antigos, permitem observar evoluções futuras (Callon, 2017: 229). 
A teoria dos agenciamentos mercantis confere bastante destaque ao processo de coprodução dos perfis (profilage), chamando atenção para o fato de que este ocorre não apenas na etapa de realização da compra/venda, mas, alastra-se para outros momentos do intercâmbio mercantil, como no caso das atividades que permitem o encontro entre financiadores e criadores de startups ou no caso de projetos de crowfunding, e de que são as plataformas de encontro que permitem esse alinhamento de posições a jusante e a montante.

No final da discussão sobre a organização dos encontros, Callon apresenta algumas inquietações quanto ao acúmulo de informações sobre os clientes pelas plataformas de encontro. Dentre essas inquietudes, destaca o reducionismo das características das pessoas, que são catalogadas por plataformas a partir de alguns atributos, como no exemplo dos tratamentos singularizados da biomedicina e os possíveis efeitos negativos do processo de singularização (intensiva) promovido pelas plataformas para as ações coletivas. Contudo, chama atenção também para a existência de lutas pelo controle dos bancos de informações operados por essas plataformas, sobre que tipo de informação é captada, analisada e exteriorizada; dizendo que esse trabalho sobre as informações é parte importante da luta

pelo controle do processo de fixação dos preços e das relações de dominação (cuja questão central é a do controle do qualcul) que se estabelece no seio dos sites de transação e entre eles (Callon, 2013: 372).

O cadrage seguinte é o que trata da atração mercantil (affectio mercatus), isto é, do conjunto de mecanismos que levam as agências a se envolverem em transações bilaterais compensadas monetariamente (Callon, 2017: 268). Para desenvolver sua argumentação, Callon começa com uma revisão da forma como a economia e a sociologia explicam a motivação dos agentes para a compra e, na sequência, a discussão dos mecanismos de envolvimento e desligamento de compradores, vendedores e bens.

Segundo o raciocínio desenvolvido, a teoria econômica abordou a questão da motivação primeiramente em termos da perspectiva da utilidade dos bens (valor-utilidade), para, em tempos mais recentes, orientar sua análise para a questão do estabelecimento da preferência dos atores, que tomam decisões em um universo complexo e incerto. No caso da sociologia, a principal característica dos estudos sobre o ato de consumo é sua identificação como manifestação de disposições incorporadas (Bourdieu, 2000) e como revelador de posições sociais. Apesar de destacar a validade relativa dessas explicações, Callon diz que a sociologia ainda 
não reconheceu a importância dos bens na dinâmica mercantil, o que foi feito pela economia, principalmente quando essa disciplina trabalha sobre os bens de adiç̧ão (Callon, 2017:203).

Para compreender esse processo de envolvimento afetivo com os bens, Callon apresentará três tipos de dispositivos que atuam na produção dos envolvimentos dos agentes com os bens - e vice-versa -, denominando-os de dispositivos de diálogo, de coprodução e de adicção.

Os dispositivos de diálogo têm por objetivo "definir, de forma progressiva, o que os clientes esperam, desejam ou querem" dos bens/serviços, fazendo com que expressem essa vontade (Callon, 2017: 296). Argumenta ainda que em seu formato inicial esses dispositivos se baseavam em relações face a face, apoiadas por algum tipo de suporte material (caso do catálogo de vendas, por exemplo), e que nas versões mais atuais, que fazem uso da internet, há uma possibilidade formidável de manter e expandir essa relação entre empresas e clientes. No caso dos dispositivos de coprodução, como o próprio nome sugere, os consumidores são convocados a participar da concepção e produção dos bens que lhes são destinados. Callon destaca que esse tipo de dispositivo se generalizou com mais força nas atividades de serviço, mas, que está presente em outros setores econômicos, pois, tornou-se uma importante ferramenta para as estratégias comerciais que buscam fidelizar os consumidores.

O terceiro dispositivo descrito é o de adicção. Nesse tipo de dispositivo, o consumidor finda por se tornar dependente do bem/serviço proposto, como nos exemplos da indústria de jogos de Las Vegas e de um banco britânico (Wonga) especializado na captação de clientes que não conseguem saldar os empréstimos tomados. Para concluir a exposição dos dispositivos, Callon afirma que é possível constatar um peso crescente dos dispositivos de adicção na produção dos envolvimentos comerciais, e que essa participação crescente coloca em questão uma série de críticas endereçadas a esses mecanismos de afetação, colocando a atividade mercantil em perigo, como mostram as denúncias sobre publicidade enganosa, manipulação de bases de dados e utilização de algoritmos para produção de novas desigualdades. Nesse sentido, a "coprodução dos bens é uma ilusão e a participação [dos consumidores] uma miragem" (Callon, 2017: 315).

O último cadrage exposto é o da formulação dos preços. De acordo com a argumentação de Callon, esse cadrage representa um avanço em relação à forma como a microeconomia e a sociologia econômica abordam a questão da formação dos preços, uma vez que mesmo por caminhos distintos ${ }^{6}$, essas perspectivas con-

\footnotetext{
6. A diferença principal consiste no fato de que a microeconomia destaca a dimensão concorrencial e as preferências individuais na formação dos preços enquanto a sociologia econômica - em suas diferentes abordagens sublinha o papel das relações sociais (regulações, relações de força, quadros culturais, redes sociais) que enquadram os agentes no intercâmbio mercantil (Callon, 2013: 389-390).
} 
sideram que o nível dos preços é determinado pelo mercado, visto somente como o encontro entre agentes da oferta e da procura.

Em consonância com a visão ampliada dos mercados que a teoria dos agenciamentos mercantis defende, o processo de formulação dos preços é considerado como derivado das práticas e estratégias de pricing elaboradas por diferentes agentes no processo de qualificação e singularização dos bens. Nesse sentido, Callon argumenta que "os preços são qualculados a partir de outros preços" (Callon, 2017: 333) e não o resultado do encontro misterioso entre blocos de oferta e demanda.

Para expor esse processo de formulação dos preços, Callon utiliza um estudo de Finez (2014) sobre a evolução do sistema de tarifação dos bilhetes de transporte da rede ferroviária francesa Société Nationale des Chemins de Fer (SNCF). De acordo com esse estudo, ao longo da história da SNCF prevaleceram três fórmulas para o estabelecimento do preço do transporte de passageiros, baseadas, respectivamente, nos princípios da perequação dos preços, no custo marginal do

7. De acordo com Finez (2014), o sistema de tarifas baseado no yield management foi desenvolvido pelas companhias aéreas norte-americanas na quadra do processo de desregulamentação do setor pela administração Reagan nos anos 1980. Nesse sistema, o preço da passagem é calculado a partir de uma tarifa básica da ligação ferroviária em questão, considerando ainda o preço de reserva, as oscilações dos fluxos de passageiros e a oferta de lugares com tarifas reduzidas (Finez, 2014: 27). transporte e no yield management ${ }^{7}$ (Callon, 2017: 342). Nesse último caso, que corresponde ao sistema atual de tarifas, o preço é singularizado de acordo com uma série de características dos clientes, a partir de algoritmos mobilizados pela SNCF, ao contrário das formulações anteriores, baseadas na distância a ser percorrida (perequação) ou no custo marginal do transporte ferroviário.

Outro aspecto que pode ser destacado a partir desse exemplo é que nesse sistema de tarifação - yield management -, o preço torna-se uma qualidade do serviço a ser vendido, o que permite mostrar que o preço se tornou uma das numerosas qualidades que permitem singularizar os bens. Para não ficar no exemplo da economia dos serviços (transporte ferroviário), Callon fala das lojas que propõem todos os produtos por um determinado valor e diz que, nesses casos, "o cliente compra o preço antes de comprar o artigo" (Callon, 2013: 393).

Essa discussão acerca da formulação dos preços pela teoria dos agenciamentos mercantis faz aparecer com força outra questão, a das relações de poder e dominação embutidas nesse processo. Para Callon isso se expressa na luta pela capacidade de formulação dos preços:

Em uma situação de dominação total (caso do cliente de um fornecedor que não possui meios de calcular ele mesmo o preço e de tentar fazer com que sua formulação seja levada em consideração), o estabelecimento do preço [...] torna-se, pelo menos nos regimes democráticos, uma questão política de forma integral (Callon, 2013: 409). 
Em termos teoricamente mais elaborados, Callon dirá que esse maior poder de formulação está associado à capacidade de certas agências (uma trading que opera no mercado mundial de grãos, por exemplo) de "relacionar e analisar o maior número de locais e de preços diferentes" (Callon, 2017: 370), retomando, de certa forma, a noção de enrôlement mobilizada em seus trabalhos sobre o processo de tradução de inovações tecnológicas (Callon, 1986).

Contudo, em consonância com essa perspectiva foucaultiana do poder, Callon afirma que existe também a possibilidade de disputa na formulação dos preços. Na primeira apresentação da teoria dos agenciamentos mercantis essa resistência é exemplificada nas ações estatais de regulação (Callon, 2013: 409), enquanto na versão mais elaborada, entidades estatais e movimentos de consumidores (como a organização UFC-Que Choisir?) aparecem como agências capazes de penetrar na caixa-preta para compreender como o preço é composto. A parte final da apresentação desse último cadrage é dedicada a explorar essa relação dialética entre opacidade e transparência ao debate no processo formulação dos preços. Por vezes, parece que há uma tendência de elementos que apontam na perspectiva da abertura do debate sobre as formulações; contudo, no fechamento da seção, CalIon dirá que o "trabalho de formulação comporta uma zona fechada irredutível", cuja explicitação completa careceria de sentido (Callon, 2017: 393).

\section{A dinâmica dos}

\section{agenciamentos mercantis}

O penúltimo capítulo do livro O domínio dos mercados é destinado a explicitar como a dinâmica dos agenciamentos mercantis pode ser operacionalizada, a partir do estudo do funcionamento de dois mercados. Antes, contudo, Callon destaca as vantagens heurísticas da utilização do conceito de agenciamento, que, ao contrário de noções concorrentes - como campo, instituição e estrutura -, permitiria a apreensão do fenômeno estudado em seus movimentos de reprodução e inovação. Contudo, antes de avançar na exposição sobre a dinâmica dos agenciamentos, ele sente a necessidade de explicitar o motivo pelo qual está abandonando o conceito de dispositivo, utilizado em estudos anteriores ${ }^{8}$.

A razão para essa substituição está relacionada com alguns fatores, dentre os quais se destaca o fato de o conceito de dispositivo separar componentes e humanos, dando primazia aos primeiros. Por conseguinte, o conceito de agenciamento teria a vantagem de não realizar essa separação e de permitir compreender as ações mercantis como estruturadas por cadrages, que "formatam o curso da ação ao mesmo tempo em que são o objeto dessa ação" (Callon, 2017: 403).

\footnotetext{
8. 0 artigo

"Os mercados econômicos como dispositivos coletivos de cálculo" é um bom exemplo do papel central do conceito de dispositivo nos estudos de Callon e colaboradores (Callon \& Muniesa 2003).
} 
Para retomar a apresentação da dinâmica dos agenciamentos, Callon dirá que esse conceito permite estabelecer o vínculo entre um conjunto de cadrages e uma ação específica, que não é necessariamente uma ação mercantil. Ou seja, existem agenciamentos voltados para questões de outra natureza, como a produção de conhecimento científico. Essa visão do agenciamento como relacionado a outros processos é importante, pois, por vezes, os componentes de um agenciamento mercantil podem estar relacionados com outros objetivos, por vezes contraditórios, de tal forma que Callon diz que é necessário utilizar termos como alinhamento e articulação para dar conta dessas características dos agenciamentos (Callon, 2017: 409).

Ao dizer que as atividades que compõem os agenciamentos podem articular-se, alinhar-se ou opor-se, Callon pergunta como essa articulação ou oposição se resolve em cada local específico de um dado agenciamento? A resposta para essa questão é dada pelo conceito (descritivo) de zona franca, que permite compreender o processo pelo qual os agenciamentos mercantis se vascularizam, mas continuam contribuindo para o desenrolar da ação coletiva mercantil.

Outro conceito central para a compreensão da dinâmica do agenciamento mercantil é o de transbordamento, que, ao lado na noção de estabilização, constitui uma das questões centrais para a compreensão do sucesso/fracasso da interação mercantil. Para discutir essa dinâmica transbordamento/estabilização e a dinâmica dos agenciamentos mercantis, Callon apresenta dois estudos que abordam o funcionamento do mercado das funerárias (França) e da construção de habitações (Inglaterra).

No caso do mercado de serviços funerários, Callon se apoia na pesquisa realizada por Pascale Trompette, que estudou o funcionamento desse mercado a partir da análise do processo de captação dos clientes (Trompette, 2005). Contudo, o que interessa a Callon nesse estudo é a descrição das modificações operadas ao longo do tempo no funcionamento do mercado de serviços funerários, pois, ela permite mostrar as mudanças no agenciamento mercantil. No primeiro momento, quando a morte ocorria principalmente nas residências familiares, o funeral era realizado por uma empresa que obtinha o monopólio para a realização dessa atividade junto à prefeitura local. Como contrapartida, essa empresa deveria garantir o enterro das pessoas sem condição de pagar (Callon, 2017: 423). Nesse caso, diz Callon, a singularização do serviço era realizada através da oferta de tipos diferenciados de enterro para os clientes, cada tipo de enterro apresentando uma formulação de preço específica, enquanto a organização do encontro mercantil era garantida pela obtenção do monopólio municipal. 
Contudo, a partir de um determinado momento, esse monopólio foi quebrado e se instaurou uma concorrência entre empresas pela captação dos cadáveres; outra mudança importante para o funcionamento do mercado foi a transferência do lugar habitual da morte, que passou a ocorrer em hospitais ou asilos. Nessa nova situação, os cadrages do agenciamento mercantil anterior precisaram ser modificados, pois a organização do encontro mercantil passou a ser realizada em câmaras-ardentes localizadas no interior ou na proximidade dos hospitais. O processo de formulação dos preços dos serviços funerários continuou opaco, reforçando a assimetria entre as empresas prestadoras do serviço e os clientes. Nesse novo tipo de agenciamento, as câmaras-ardentes aparecem como centrais para sua estabilização, mas, são objeto de contestação por parte das empresas concorrentes, que veem no estabelecimento desse dispositivo sociotécnico nas relações entre funcionários dos hospitais, das delegacias de polícia e das funerárias uma forma velada de monopólio (Trompette, 2005).

Ao final da exposição, Callon argumenta que a análise do desenvolvimento do mercado de funerais possibilita a observação da evolução dos cadrages, com destaque para o processo de passiva-ação, que, no início, percorria um circuito curto (familiares do morto até a igreja) e, nos tempos atuais, percorre um circuito mais longo (hospitais ou asilos, câmaras-ardentes e cemitério ou crematório). Nesse sentido, destaca o papel central desempenhado pelas câmaras-ardentes e o alinhamento que elas possibilitam dos cadrages na constituição do novo agenciamento mercantil (Callon, 2017: 427).

Se o caso do mercado de serviços funerários chama atenção pelas mudanças, no exemplo do mercado de construção civil na Inglaterra o aspecto ressaltado é o da estabilidade. A partir de estudo feito por Lovell e Smith, Callon discute os motivos pelos quais empresas que trabalham com a tecnologia de pré-moldados não conseguem se estabelecer nesse mercado. A resposta apresentada está relacionada à invisibilidade e exclusão do cálculo dos custos de fabricação de elementos que fazem a força das empresas de pré-moldados. Destarte, Callon argumentará que apesar da constatação de que a construção pré-moldada apresenta menores defeitos e cumpre melhor os prazos acordados, a indústria tradicional da construção consegue manter-se, pois, "nos cálculos e avaliações praticadas pelo setor, esses eventos não são levados em consideração" (Callon, 2017: 429). Ou seja, apesar das críticas das empresas de pré-moldados, os dispositivos de cálculo e de formulação de preços continuam alinhados segundo o padrão tradicional do setor, elementos que são desconsiderados nas explicações sociológicas e econômicas tradicionais, que apontariam como fatores de estabilização, respectivamente, a aliança entre grupos de interesses e a maior competitividade do setor tradicional, considerando a estrutura de custos visíveis. 


\section{A dimensão política da abordagem dos agenciamentos mercantis}

Na conclusão do artigo em que apresentou a teoria dos agenciamentos mercantis, Callon deixou clara a dimensão política da abordagem, que tem o propósito de interferir no funcionamento da ação mercantil, a partir de uma perspectiva mais profunda do que aquela proporcionada pela abordagem dos mercados-interface (Callon, 2013: 434). Enquanto essa última focaliza sua atuação na análise das questões relativas aos preços e ao ajustamento entre oferta e demanda, o approach dos agenciamentos mercantis abre espaço para um leque maior de discussões (e intervenções), partindo da questão da qualificação dos bens, passando pelo debate sobre as agências de cálculo, das modalidades de envolvimento entre agentes/bens, até chegar à questão central da formulação dos preços. No capítulo final do livro O domínio dos mercados, Callon retoma essa discussão e diz que apesar de as possibilidades de intervenção na organização dos agenciamentos mercantis serem múltiplas, a questão central a ser respondida está relacionada com a pergunta sobre "quais bens devem ser produzidos, para quais agentes e a quais preços?” (Callon, 2017: 433).

Para dar conta desse debate, o autor sugere um roteiro, denominado de "ciclo de base da engenharia política dos agenciamentos mercantis", a partir do qual acredita ser possível esclarecer os mecanismos pelos quais certas concepções teóricas - de especialistas ou de profanos - podem ser levadas em consideração no estabelecimento dos agenciamentos mercantis. O esquema proposto é baseado em um ciclo de seis etapas, começando pela formulação de questões, passando em seguida pela organização do debate acerca dessas questões, pelo trabalho de teorização (aberta e/ou confinada), pelo estabelecimento de controvérsias, alianças e confrontações, pela transformação do tema em questão, findando com o

9. Esse ciclo retoma, de certa forma, a reflexão apresentada por Callon e colaboradores acerca das controvérsias científicas e tecnológicas, com a sugestão da organização de fóruns híbridos, capazes de promover, ao mesmo tempo, uma democracia dialógica e resultados eficazes (Callon et alii, 2001). estabelecimento e difusão dos novos cadrages, que estabilizarão a questão, até o surgimento de uma nova problematização9.

Para mostrar a produtividade dessa perspectiva de intervenção nos debates sobre o funcionamento dos mercados, pensados como agenciamentos mercantis, Callon proporá a discussão de questões relativas ao funcionamento do mercado financeiro, das estratégias de contenção do aquecimento climático e da constituição de mercados para produtos geneticamente modificados.

Sem entrar nos detalhes de cada uma das situações analisadas - que Callon diz que aprofundará em uma próxima publicação -, gostaria de destacar alguns ensinamentos das questões analisadas. Destarte, no caso da discussão sobre o fun- 
cionamento dos mercados financeiros, Callon diz que seria necessário ir além da questão da eficiência dos mercados e abordar o funcionamento do mercado, considerado não como modelo abstrato, mas na perspectiva dos agenciamentos mercantis, ou seja, a partir da descrição de "seus equipamentos, dos cadrages e transbordamentos que suscitam" (Callon, 2017: 450).

Na discussão acerca da questão do aquecimento climático global, a sugestão é a de evitar um debate que oponha propostas fechadas ${ }^{10}$, de forma a avançar na elaboração de alternativas através de pequenos avanços progressivos, através da elaboração de cadrages que apontem no sentido da redução da emissão dos gases de efeito estufa, como, por exemplo, a consideração das emissões na contabilidade das empresas, de forma a permitir a reorientação das estratégias industriais (Callon, 2017: 466).

No último caso apresentado, Callon discute a possibilidade da convivência entre dois agenciamentos mercantis, o dos produtos geneticamente modificados e o da agricultura natural. Após criticar como a teoria econômica analisa a questão da concorrência entre diferentes configurações mercantis, diz que a questão que se coloca "é a de imaginar mecanismos capazes de prevenir a produção de fechamentos" ou irreversibilidades nos agenciamentos (Callon, 2017: 473) ${ }^{11}$.

Para encerrar a discussão, Callon argumenta que o exercício teórico realizado demonstra a possibilidade de impor objetivos políticos constrangedores aos agenciamentos mercantis, e que uma "organização adequada e finamente calibrada das atividades mercantis", contribuiria de forma mais efetiva para essa tarefa do que "simples medidas regulamentares" (Callon, 2017: 475).

\section{Conclusão}

A abordagem teórica desenvolvida por Callon e colaboradores - também conhecida como teoria da performatividade - constitui, junto com a análise das redes sociais e as abordagens institucionalistas e estruturalistas, o principal arcabouço teórico elaborado pela nova sociologia econômica para o estudo do funcionamento dos mercados (Fourcade, 2007; Beckert, 2009; Fligstein \& Dauter, 2012; Steiner, 2018).

Em artigo que tem por objetivo assinalar a contribuição da sociologia dos mercados para a teoria social contemporânea, Marion Fourcade (2007) analisa três abordagens teóricas da nova sociologia econômica: a análise de redes sociais (teoria do embeddedness relacional); a teoria os campos; e os estudos da pers-
10. As principais soluções apresentadas para enfrentar a questão do aquecimento climático global são: a elaboração de uma regulamentação estatal com limites para emissões dos gases de efeito estufa; a criação de um mercado de quotas das emissões (por país ou por setor industrial); e a criação de uma taxação sobre as emissões (Callon, 2017: 454).

11. Callon apresenta algumas indicações nesse sentido, tais como a organização de encontros favorecendo a dinâmica dos circuitos curtos da agricultura natural, mas que permitam também aos agricultores interessados a possibilidade de acesso às sementes transgênicas, caso isso seja de seu interesse. 
12. Em texto escrito para um manual de sociologia econômica, Fabian Muniesa e Michel Callon (2009: 296) dizem que ao invés do termo performativité (performatividade) preferem utilizar o de performation (performação), uma vez que esse último designa melhor o fato que "performer (performar) é uma ação, um trabalho".

13. Não por acaso um livro organizado por Franck Cochoy, no qual Callon escreveu o prefácio, foi intitulado Du lien marchand: comment le marché fait la société (Callon, 2012). pectiva da performatividade ${ }^{12}$. A autora argumenta que enquanto os trabalhos da análise de redes e da teoria dos campos procuram estudar como as estruturas sociais produzem os mercados, a escola da performatividade inverte esses termos e mostra como os mercados produzem a sociedade ${ }^{13}$. Nesse sentido, diz que essa abordagem apresentaria uma teoria da modernidade neofoucaultiana, tendo como principais características a dimensão central assumida pelos mercados (gouvernementalité néoliberale) e o papel dos dispositivos coletivos de cálculo (Fourcade, 2007: 1026).

Contudo, para o debate aqui proposto, a parte mais interessante desse artigo consiste na discussão que essa autora faz acerca das principais forças e fragilidades de cada perspectiva teórica, bem como das possibilidades de diálogo entre elas. No que concerne à teoria da performatividade, Fourcade (2007: 1025) argumentou que essa possui o mérito de destacar como a ciência econômica atua no processo de formatação dos fenômenos econômicos, mas que apresenta algumas fragilidades relacionadas à desconsideração da influência do contexto, das relações de poder (Bourdieu) e dos valores (Zelizer) no processo de performatização.

De acordo com Fligstein e Dauter (2012), a ideia central da abordagem performativista é que a ação econômica está intimamente relacionada à noção de cálculo e que a forma como esse cálculo é realizado "é crucial para a compreensão da estrutura dos mercados" (Fligstein \& Dauter, 2012: 483). Indicam ainda como uma das principais contribuições dessa abordagem o destaque que conferem ao papel da ciência econômica na "constituição das ferramentas culturais" (Fligstein \& Dauter, 2012: 494) que moldam o funcionamento dos mercados. Como ponto cego dessa perspectiva, evidenciam a pequena importância conferida a temas como a confiança, a legitimidade e a dependência de recursos e dizem que suas análises "geralmente ignoram os possíveis efeitos do governo e da legislação" na estruturação dos mercados (Fligstein \& Dauter, 2012: 483).

Ao discutir os elementos centrais para o estabelecimento da ordem social dos mercados, Beckert aponta o papel desempenhado por "redes sociais, normas, estruturas cognitivas e instituições" na redução das contingências presentes no processo de coordenação dos atores (Beckert, 2009: 251), identificando a contribuição da teoria da performatividade como "enraizamento (embeddedness) cognitivo". Contudo, ao discutir os três problemas centrais para o funcionamento dos mercados - a questão do valor dos bens e os temas da coordenação e competição dos atores econômicos -, Beckert confere pouca importância aos estudos da performatividade, citando-os apenas na discussão da qualificação e estabilização 
da identidade dos bens no mercado, quando cita a discussão ocorrida por colaboradores de Callon acerca do "attachement (associação) simbólico do valor aos produtos" (Beckert, 2009: 256) ${ }^{14}$.

Em entrevista acerca de seu livro mais recente - Imagined futures. Fictional expectations and capitalist dynamics -, quando perguntado acerca da relação entre seu conceito de expectativas ficcionais (Beckert, 2017) e o debate sobre a performatividade das ciências econômicas, Beckert afirma ter restrições em relação a essa perspectiva analítica, criticando o peso exagerado que ela confere à capacidade da teoria econômica em moldar a realidade, desconsiderando o papel desempenhado por outros dispositivos cognitivos nesse processo (Finez \& Naulin, 2018: 158).

Os primeiros trabalhos de Steiner $(1999,2010)$ sobre a sociologia dos mercados conferem pouca importância aos estudos de Callon, destacando de forma rápida a importância do "enraizamento econômico das relações econômicas" no processo de construção social dos mercados (Steiner, 1999:101), ou sublinhando o papel desempenhado por profissionais do mercado na construção da qualidade dos bens e na captura de clientelas (Steiner, 2005: 53). Contudo, em período mais recente, influenciado pelo desenvolvimento da proposta da abordagem dos agenciamentos mercantis, Steiner vem conferindo mais relevância à teorização calloniana, considerando-a como uma abordagem de grande relevância e uma "contribuição de porte geral para a sociologia dos mercados" (Steiner apud Berkowitz, 2014: 17) ${ }^{15}$.

Após a realização desse breve balanço, a questão a ser agora apresentada diz respeito aos ganhos analíticos obtidos com o desenvolvimento da abordagem proposta por Callon, bem como de suas fragilidades e insuficiências.

Creio que o principal ganho se situa no estabelecimento de parâmetros - os cadrages - para uma descrição mais global e, ao mesmo tempo, mais detalhada do processo de qualificação e singularização dos bens, ao pensar as transações mercantis como processo complexo, envolvendo uma série de atividades que se desenvolvem a montante e a jusante daquelas que são consideradas e analisadas pela teoria mercado-interface.

Outra contribuição importante, e que pode ser vinculada à crítica realizada por Fourcade (2007) aos estudos performativistas, relaciona-se a um investimento mais claro no debate sobre o papel das relações de poder no interior dos agencia-
14. Em introdução a livro sobre a construção da qualidade dos bens, escrito em coautoria com Christine Musselin, Jens Beckert confere mais destaque aos trabalhos de Callon e colaboradores,

sublinhando

a importância dos dispositivos de medida nos processos de qualificação dos bens e, por conseguinte, na estruturação dos mercados (Beckert \& Musselin, 2013).

15. Em contraste com o lugar secundário ocupado pela abordagem calloniana na coletânea de trabalhos representativos da sociologia econômica francesa que Philippe Steiner organizou com François Vatin (Steiner \& Vatin, 2009). 
16. Em resenha sobre L'emprise des marchés, Philippe Steiner dirá que a sociologia calloniana não identifica de forma precisa a natureza das relações de força presentes nos agenciamentos mercantis, que ele aborda a realidade (sociotécnica) de forma demasiadamente fluida, como um "tecido sem costura" (Steiner, 2018: 187).

17. Ao discutir a dinâmica dos agenciamentos, Callon (2017: 409) afirma: "Falar de agenciamento significa aposentar análises em termos de esferas, de normas ou de valores, de cités ou ainda de modos de regulação ou de coordenação". mentos mercantis ${ }^{16}$. Nesse sentido, ao discutir as disputas pela capacidade de formulação dos preços (agências de cálculo), Callon mobilizará a teoria pragmática da captura (emprise) de Francis Chateauraynaud (2015), dizendo que a captura é uma ação que resulta "de um processo relacional que conduz à tomada de controle de experiências do mundo social" (Callon, 2017: 372).

Apesar desses avanços, creio que duas críticas podem ser adiantadas em relação à abordagem dos agenciamentos mercantis: a primeira diz respeito à natureza dos fenômenos econômicos analisados; a segunda, em relação ao debate acerca da associação entre os dispositivos sociotécnicos e o mundo social.

Apesar de Callon sugerir que os mercados pensados como relações bilaterais representam a maior parte dos intercâmbios mercantis, os diversos exemplos mobilizados ao longo do livro dizem principalmente respeito a atividades que envolvem a prestação de serviços com utilização de algoritmos e que dificilmente poderiam ser caracterizadas como mercados comuns (Roth, 2016). Nesse sentido, concordo com Steiner, quando diz que os exemplos mobilizados por Callon pertencem ao universo da chamada "Economia 2.0" (Steiner, 2018: 192).

A segunda questão é mais profunda, pois, discute a primazia conferida pelos atores da teoria do ator-rede e dos estudos performativistas aos dispositivos (ou agenciamentos) sociotécnicos em relação ao mundo social ${ }^{17}$. Aqui, retomo a crítica elaborada Nicolas Brisset (2014) quanto à possibilidade de pensar a autonomia desses dispositivos de performatividade em relação a fatores sociais, pois, como mostra esse autor, a partir do exemplo da elaboração de um dispositivo de pareamento entre doadores/receptores de rins humanos, o processo de estabelecimento desse tipo dispositivo sociotécnico pressupôs um acordo (convenção) sobre sua natureza (mercantil versus não mercantil). No exemplo citado por esse estudo, Brisset (2014: 240) mostra como certos valores presentes na sociedade norte-americana fizeram com que o dispositivo de pareamento escolhido funcionasse segundo a perspectiva da doação ao invés de seguir uma lógica comercial, em razão da repugnância social ante a possibilidade de tratar os órgãos humanos como mercadorias.

Por fim, mas não menos importante, creio que é necessário problematizar a tese calloniana de que a intervenção nos agenciamentos mercantis seria mais efetiva do que as tentativas de regulação do mercado por normas (Callon, 2017: 475). Como indicam Ali Douai e Mathieu Montalban (2015), para o caso dos mecanismos de pagamento por serviços ambientais, a abordagem performativista desconside- 
ra o contexto político que antecede o momento de surgimento dos dispositivos sociotécnicos criados, transferindo o momento da luta política para o âmbito da formatação do dispositivo. De forma semelhante, procurei mostrar que o processo de construção dos dispositivos sociotécnicos da certificação florestal (Carneiro, 2017) e das concessões florestais (Carneiro, 2012) é inseparável do contexto institucional no qual foram gestados, bem como das lutas entre diferentes agentes, situados em posições distintas no mundo social (empresas, ONGs ambientalistas, agentes estatais), que participaram desses processos.

\section{Referências}

AKRICH, Madeleine. Débordements. Mélanges offerts à Michel Callon. "Collection Sciences Sociales". Paris: Presses des Mines, 2010.

BECKERT, Jens. Reimaginando a dinâmica capitalista. Expectativas ficcionais e o caráter aberto dos futuros econômicos. Tempo Social, v. 29, n. 1, p. 165-189, 2017.

- The social order of markets. Theory and Society, v. 38, n. 3, p. 245-269, 2009.

BECKERT, Jens; MUSSELIN, Christine. Introduction. In: BECKERT, Jens; MUSSELIN, Christine (Eds.). Constructing quality: the classification of goods in markets, $\mathrm{p}$. 1-40. Oxford (UK): Oxford University Press, 2013. Disponível em: <https://spire. sciencespo.fr/hdl:/2441/58lq63me7n8bipb7k8523o1org/resources/beckert-musselin-introduction-constructing-quality-cb-jb-cm.pdf>. Acesso em: 20 Jan. 2018.

BERKOWITZ, Héloise. Qu'est-ce qu'un agencement marchand? Débat avec Michel Callon. Le Libellio a'AEGIS, v. 10, n. 2, p. 15-28, 2014.

BOISARD, Pierre; LETABLIER, Marie-Thérèse. Un compromis d'innovation entre tradition et standardisation dans l'industrie laitière. Cahiers du Centre d'Études de l'Emploi. Justesse et Justice dans le Travail, v. 33, p. 209-218, Paris: Presses Universitaires de France, 1989.

BOURDIEU, Pierre. Les structures sociales de l'économie. Paris: Les Éditions du Seuil, 2000.

BRISSET, Nicolas. Performer par le dispositif: un retour critique sur la théorie de la performativité. L'Année Sociologique, v. 64, n. 1, p. 217-246, 2014.

CALLON, Michel. L'emprise des marchés. Comprendre leur fonctionnement pour pouvoir les changer. Paris: La Découverte, 2017. 
- Qu'est-ce qu'un agencement marchand? In: CALLON, M. et alii (Dirs.). Sociologie des agencements marchands - textes choisis, p. 325-440. Paris: Presses des Mines, 2013.

- Postface. In : COCHOY, Franck (Dir.). Du lien marchand : comment le marché fait la société, p. 343-362. Toulouse: Presses Universitaires du Midi, 2012.

- Postface - La formulation marchande des biens. In : VATIN, F. (Dir.). Évaluer et valoriser: une sociologie économique de la mesure, p. 247-269. Toulouse: Presses Universitaires du Midi, 2009.

— . Entrevista com Michel Callon: dos estudos de laboratório aos estudos de coletivos heterogêneos, passando pelos gerenciamentos econômicos. Sociologias, n. 19, p. 302-321, Porto Alegre, 2008.

- Sociologie de l'acteur réseau. In : AKRICH, M.; CALLON, M.; LATOUR, B. (Dirs.). Sociologie de la traduction - textes fondateurs, p. 267-276. Paris: Presses des Mines, 2006.

. Introduction. The embeddedness of economic markets in economics. In: CALLON, M. The laws of markets, p. 1-57. Oxford (UK): Blackwell, 1998a.

_ . An essay on framing and overflowing: economic externalities revisited by sociology. In: CALLON, M. (Ed.). The laws of markets, p. 244-269. Oxford (UK): Blackwell, 1998b.

—. Réseaux technico-économiques et irréversibilités. In: BOYER, R. et alii (Dirs.). Les figures de l'irréversibilité en économie, p. 195-230. Paris: École des Hautes Études en Sciences Sociales, 1991.

— Élements pour une sociologie de la traduction. La domestication de coquilles Saint-Jacques et des marins-pêcheurs dans la baie de Saint-Brieuc. L'Année Sociologique, n. 36, p. 169-208, 1986

CALLON, Michel.; MÉADEL, Cécile; RABEHARISOA, Vololona. L'économie des qualités. In: CALLON, M. et alii (Dirs.). Sociologie des agencements marchands - textes choisis, p. 143-170. Paris: Presses de Mines, 2013, p. 143-170.

CALLON, Michel; MUNIESA, Fabian. Les marchés économiques comme dispositifs collectifs de calcul. Réseaux, v. 21, n. 122, p. 191-233, 2003. Disponível em: <https://www.cairn.info/load_pdf.php?ID_ARTICLE=RES_122_0189>.

CALLON, Michel ; LASCOUMES, Pierre ; BARTHE, Yannick. Agir dans un monde incertain. Essai sur la démocratie technique. Paris: Les Éditions du Seuil, 2001. 
CARNEIRO, Marcelo S. O papel dos dispositivos de prescrição e julgamento no funcionamento dos mercados: o caso da certificação florestal. Revista Tomo [Online], v. 30, p. 267-302, 2017.

— Entre o Estado, a sociedade e o mercado: análise dos dispositivos de governança da indústria florestal na Amazônia. Caderno CRH [Online], v. 25, p. 73-86, 2012.

CHATEAURAYNAUD, Francis. L'emprise comme expérience. Enquêtes pragmatiques et théories du pouvoir. Sociologies, [Online], 2015. Disponível em: <http:// journals.openedition.org/sociologies/4931>. Acesso em: 20 Jan. 2018.

COCHOY, Frank. Une sociologie du packaging ou l'âne de Buridan face au marché. Paris: Presses Universitaires de France, 2002.

—. Le "qualcul" économique du consommateur: ce qui s'échange autour d'un chariot. L'Année Sociologique, v. 61, n. 1, p. 71-101, 2011.

DIAZ-BONE, Rainer; THEVENOT, Laurent. La sociologie des conventions. La théorie des conventions, élément central des nouvelles sciences sociales françaises. Trivium [en ligne], n. 5, 2010. Disponível em: <http://trivium.revues.org/3626>. Acesso em: 10 Set. 2014

DUMEZ, Hervé; JEUNEMAITTRE, Alain. Quand l'économie échoue à être perfomative. Une étude de cas. In: AKRICH, M. et alii (Dirs.). Débordements. Mélanges offerts à Michel Callon, p. 129-142. Paris: Presses des Mines, 2010.

DOUAI, Ali; MONTALBAN, Mathieu. Construction (sociale) des marchés et regulations environnementales: un point de vue intitutionnaliste. Revue Internationale de Droit Économique, v. 29, n. 2, p. 211-235, 2015.

FINEZ, Jean. La construction des prix à la SNCF, une socio-histoire de la tarification. De la pérequation au yield management (1938-2012). Revue Française de Sociologie, v. 55, n. 1, p. 5-39, 2014. Disponível em: <https://www.cairn.info/revue-francaise-de-sociologie-2014-1-page-5.htm>. Acesso em: 10 Jan. 2018.

FINEZ, Jean; NAULIN, Sidonie. Entretien avec Jens Beckert. «Orienter l'action économique vers le futur est un trait central du capitalisme moderne». Revue Française de Socio-Économie, n. 21, p. 151-164, 2018.

FLIGSTEIN, Neil; DAUTER, Luke. A sociologia dos mercados. Caderno CRH, v. 25, n. 66, p. 481-503, 2012. 
FOURCADE, Marion. Theories of markets and theories of society. American Behavioral Scientist, n. 50, p. 1015-1034, 2007.

GARCIA-PARPET, Marie-France. Le marché de l'excellence: les grands crus à l'épreuve de la mondialisation. Paris: Les Éditions du Seuil, 2009.

GEERTZ, Clifford. Le Souk de Sefrou. Sur l'économie du bazar. Paris: Éditions Bouchène, 2003.

HERLEM, Kévin. Une autre approche des marchés. À propos de sociologie des agencements marchands de Michel Callon. Le Libellio a'AEGIS, v. 10, n. 2, p. 7-14, 2014. Disponível em: <http://lelibellio.com/wp-content/uploads/2013/02/Le-Libellio-vol.-10-n\%C2\%B0-2-pages-5-\%C3\%A0-28-2014-DOSSIER-Les-Agencements-marchands.pdf>. Acesso em: 20 Mar. 2018.

LE VELLY, Ronan. Sociologie du marché. Paris: La Découverte, 2012.

MUNIESA, Fabian; CALLON, Michel. La performativité des sciences économiques. In : STEINER, P. ; VATIN, F. (Dirs.). Traité de sociologie économique, p. 289-324. Paris : Presses Universitaires de France, 2009.

POLANYI, Karl. A grande transformação: as origens de nossa época. Rio de Janeiro: Campus, 2000.

ROTH, Alvin E. Como funcionam os mercados: a nova economia das combinações e do desenho dos mercados. São Paulo: Portfolio-Penguin, 2016.

_. Les sociologies économiques relationnelles: reflexions sur trois ouvrages récents. Revue Française de Socio-Économie, n. 21, p. 185-196, 2018.

— Marché, transaction marchande, et non marchande. HATCHUEL, A.; FAVERAU, O.; AGGERI, F. (Dirs.). L'activité marchande sans le marché ? Colloque de Cerisy, p. 147-157. Paris: Presses des Mines, 2010.

- Le marché selon la sociologie économique. Revue Européenne des Sciences Sociales, v. 18, n. 132, p.31-64, 2005.

—. La sociologie économique. Paris: La Découverte, 1999.

STEINER, Philippe; VATIN, François. Introduction - Le fait économique comme fait social. In : STEINER, P.; VATIN, F. (Dirs.). Traité de sociologie économique, p. 1-12. Paris: Presses Universitaires de France, 2009. 
THÉVENOT, Laurent. L'action au pluriel. Sociologie des régimes d'engagement. Paris: La Découverte, 2006.

TROMPETTE, Pascale. Une économie de la captation: les dynamiques concurrentielles au sein du secteur funéraire. Revue Française de Sociologie, v. 46, n. 2, p. 233-264, 2005. Disponível em: <https://www.cairn.info/revue-francaise-de-sociologie-1-2005-2-page-233.htm>. Acesso em: 15 Jan. 2018.

(c) (1) (9) 
